Doc. dr. Hajrudin Hodžić ${ }^{1}$

\title{
IBN-MALIK I NJEGOVA ALFIYYA
}

\section{Sažetak}

Ibn-Malik je živio u XIII stoljeću, odnosno VII po hidžri i svojim radom $i$ naučnim doprinosom u potpunosti je obilježio stoljeće u kojem je živio.

Njegov naučni život je bio izuzetno plodonosan. Discipline u kojima se isticao je obogatio izuzetnim djelima, koja su pronašla plodno tlo kod generacija koje su došle nakon njega. Pisao je djela iz oblasti gramatike arapskog jezika, filologije, arapske metrike, kiraeta $i$ hadisa.

Iza sebe je ostavio brojna naučna djela, neka u formi proze, a neka o formi "edukativne poezije“, ali je daleko najznačajnije djelo koje ga je proslavilo $i$ sačuvalo spomen na njega do današnjih dana - jeste njegovo djela Alfiyya.

Zbog sveukupnog doprinosa gramatici arapskog jezika, mnogi ga svrstavaju odmah iza Sibavejha, oca arapske gramatike, a njegov život porede sa početkom nove faze u povijesti arapske gramatike.

Ključne riječi: arapski jezik, Ibn-Malik, Alfiyya, komentari Alfiyye, Andaluzija

\section{Uvod}

Ibn-Malik ('Ibn-Mālik) je živio u XIII stoljeću. Svoju mladost je proveo u rodnom gradu Jaénu, da bi nakon ratnih dešavanja i čestih blokada rodnog grada, ali i drugih gradova, bio prisiljen napustiti svoje rodno mjesto i zaputiti se prema mirnijim zemljama muslimanskog Istoka.

Ukoliko analiziramo stanje Andaluzije u vrijeme u kojem je živio IbnMalik, naći ćemo da su historijske okolnosti u Andaluziji bile krajnje teške, jer je Andaluzija prolazila kroz jedan od najkritičnijih perioda, gdje je značajan broj njenih gradova već bio u rukama Kraljevine Kastilije. Upravo je njegov rodni grad, Jaén, bio pod opsadom duži

${ }^{1}$ Islamski pedagoški fakultet u Bihaću. 
period, pa je Ibn-Malik, nakon deblokade, zajedno sa svojim brojnim sugrađanima, napustio svoj rodni grad i zaputio se na Istok.

$\mathrm{Na}$ Istoku je stupio u kontakt sa naučnim velikanima toga vremena i učeći od njih izrastao u jednog od najvećih filologa u povijesti arapskog jezika. O njegovom naučnom ugledu najbolje govori podatak da su ga mnogi smatrali najvećim filologom svoga vremena, ili, kako to neki navode, najvećim filologom VII hidžretskog stoljeća, što je ogromno priznanje za njegov naučni angažman.

\section{Biografija}

Njegovo potpuno ime je Džemaluddin Muhammed b. Abdullah b. Malik al-Ṭa'i al-Džijani (Ğamāl al-dīn Muhammad 'ibn 'Abdullāh 'ibn Mālik al-Tā'i al-Ğiyāni), poznatiji kao Ibn-Malik. Kao što stoji u samom imenu, Ibn-Malik vodi porijeklo iz nadaleko poznatog arapskog plemena Taj' (al-Țay'). Rođen je 1203. godine (600. godine po hidžri) u Jaénu (poznatijem kod Arapa kao جِيَّان) na jugu Španije na području Andaluzije.

Iako se o periodu života Ibn-Malika, kojeg je provedeo u Andaluziji zna poprilično malo, u svom rodnom mjestu Ibn-Malik je, kako se navodi u njegovoj biografiji, naučio Kur'an napamet, osnovne naučne discipline, nakon čega je značajan dio svoje mladosti proveo kod tadašnjih andalužanskih učenjaka, poput Omer b. Muhammed al-Šelevbina ('Omar 'ibn Muḥammad al-Šalawbīn) (645. h.) i Sabit b. Hijara (Tāābit 'ibn Hiiyār) (628. h.).

Kulturno-povijesni period u kojem je živio odigrao je veoma bitnu ulogu u trasiranju njegovog životnog i naučnog puta, jer su tadašnja dešavanja, što će povijest kasnije potvrditi, bila sudbonosna, posebno za muslimane tadašnje Andaluzije.

Zbog nestabilnih prilika u Andaluziji, kao i opsade njegovog rodnog grada, Ibn-Malik se zapućuje u Šam u potrazi za mirnom naučnom oazom gdje će nastojati da utoli svoju žeđ za naučnim istinama, što će se ispostaviti da je bila odlična odluka, s obzirom na rezultate koje je postigao tokom boravku u spomenutim krajevima.

U Halepu je imao priliku da proširi svoje naučne vidike, jer je bio učenik velikanima svoga vremena: Osmana b. Omera ('Oțāan 'ibn 
'Omar), poznatijeg kao Ibn al-Hadžiba (1249. g.) i Muveffakuddina Ibn Je'iša (Muwaffaq al-dīn 'Ibn Ya'īš) (1245. g.). Tokom svoga boravka u tom gradu njegov naučni ugled ga je pretekao u ostale gradove i regije, a učenici željni znanja su dolazili iz drugih gradova kako bi imali čast da, bar na kratko vrijeme, budu njegovi učenici.

Već tokom tog perioda važio je za stručnjaka i autoriteta u mnogim oblastima, poput kiraeta, morfologije i sintakse arapskog jezika, kao i arapske poezije, koju je vrlo često koristio kao argument u jezičkom normiranju.

Nakon Halepa, jedan period svoga života proveo je u Hami, gradu na zapadu Sirije, gdje je predvodio halke i držao predavanja iz domena arapskog jezika i kiraeta, nakon čega odlazi u Kairo, gdje ostvaruje kontakte sa kairskim učenjacima $\mathrm{i}$ sa njima razmjenjuje stavove $\mathrm{u}$ pogledu naučnih pitanja.

Najplodonosniji dio svoga života, a ujedno i svog dugog putovanja, okončava u Damasku, gdje je u čuvenoj Emevijskoj džamiji držao brojna predavanja, a vrhunac svoje naučne slave postiže imenovanjem za voditelja i naučnog autoriteta čuvene Velike Adilijske škole (alMadrasa al-'adiliyya al-kubra), što je počast koja su ukazuje veoma rijetkim osobama i što govori da mu u tom periodu nije bilo premca, kako ističe nekoliko autora.

S obzirom na to da je tokom svog boravka bio najistaknutiji stručnjak na polju arapske gramatike i drugih naučnih disciplina, kao i zbog činjenice da je vodio prestižnu školu al-Adiliyyu, to mu je omogućilo da ima učenike čija će imena ostati upisana zlatnim slovima u povijest različitih naučnih disciplina, a među njima se najviše ističu čuveni gramatičar Ibnun-Nahhas ('Ibn al-Naḥhās) (1299. g.), Badruddin b. Džema'a (Badr al-dīn 'ibn Ğamā'a) (1333. g.), tadašnji vrhovni kadija Egipta i Muhammed Bedruddin (Muhammad Badr al-dīn) (1287. g.), Ibn-Malikov sin, koji je napisao komentar Alfiyye, kao i čuveni i nadaleko poznati Muhjiddin al-Nevevi (Muhȳi al-dīn al-Nawawi) (1277. g.).

Osim gramatike, koja ga je proslavila, Ibn-Malik je bio odličan poznavalac arapske poezije, kira'eta, kao i hadiskih predaja. 
Ugledni svjetski arabisti nisu krili riječi hvale na račun Ibn-Malika. Ševki Dajf (Šawqī al-Dayf) za njega je rekao: „Prvak svih gramatičara i filologa svoga vremena. “2 Naš slavni arabista Teufik Muftić za njega je rekao: „Slavu najvećeg filologa svog vremena uživao je Ğamāl aldīn Muhammad 'ibn Mālik.“3

Zbog sveukupnog doprinosa gramatici arapskog jezika, mnogi ga svrstavaju odmah iza Sibavejha, oca arapske gramatike, a njegov život porede sa početkom nove faze u povijesti arapske gramatike. Kao da je povijest arapske gramatike podijeljena na dva dijela: na čelu prvog neprikosnoveno stoji Sibavejh, a na čelu drugog Ibn-Malik.

Neki autori, poput Jusufa Hulejfa (Yūsuf Hulayf), smatraju sretnom okolnošću da su se temelji i metodologija različitih gramatičkih škola jasno definisali prije pojave Ibn-Malika, da bi on, nakon uvida $u$ prethodna ostvarenja, dao svoj jasan doprinos i značajno unaprijedio arapsku gramatiku. Upravo taj doprinos je prepoznat od strane narednih generacija, koje su promovirale njegova djela putem brojnih komentara i osvrta.

Bibliografi u svojim djelima navode da je izuzetno mnogo čitao, uvijek se referirao na relevantne izvore, a nikada ne bi nešto zapisao prije nego li provjeri ispravnost navoda kojeg ima namjeru navesti u svojima djelima.

Isticao se, između ostalog, posebnim darom za poeziju, jer je ogroman broj stihova koji su korišteni za normiranje pravila arapskog jezika, do te granice da bi se prisutni zapitali odakle dolazi sa svim tim! Kao pokazatelj kontinuiranog ličnog usavršavanja, bibliografi navode podatak da je u danu u kojem je umro naučio osam novih stihova.

Ovaj čuveni filolog, porijeklom Andalužanin, svoj naučni put okončao je 1275. godine (672. h.g.) u Damasku, ostavljajući iza sebe naučno blago koje će ga proslaviti među narednim pokoljenjima. Dženaza nam mu je klanjana u Emevijskoj džamiji 12. ša'bana 672. h.g., tj. 21. februara 1274. godine.

2 Dayf, Šawqī, Al-Madāris al-naḥwiyya, Dār al-ma‘ārif, Al-țab‘a al-rābi‘a, Al-Qāhira, 1979., ș. 309.

${ }^{3}$ Muftić, Teufik, Gramatika arapskog jezika, Ljiljan, Sarajevo, 1998., str. 30. 


\section{Bibliografija}

Ibn-Malikov život je bio izuzetno plodonosan. Discipline u kojima se isticao je obogatio izuzetnim djelima, koja su pronašla plodno tlo kod generacija koje su došle nakon njega. Pisao je djela iz oblasti gramatike arapskog jezika, filologije, arapske metrike, kiraeta i hadisa.

Osim Alfiyye, o kojoj ćemo opširnije govoriti, Ibn-Malik je napisao djela iz svih ovih nabrojanih naučnih oblasti, a pojedini autori navode da je autor više od trideset djela iz različith naučnih oblasti. Neka od tih djela su napisana u proznoj, a druga u peotskoj formi.

Jedno od najznačajanijih djela, nakon Alfiyye, jeste djelo al-Kāfiya alŠăfiya, koje predstavlja širu i obimniju verziju Alfiyye, jer al-Käfiya ima oko 3000 stihova, dok Alfiyya ima oko 1000, tako da je Alfiyya jedan vid sižea djela al-Käfiya.

Jusuf Hulejf, profesor na Univerzitetu u Kairu, smatra da je njegovo djelo iz oblasti arapske gramatike Tashīl al-fawā'id wa takmīl almaqāsid ili ukratko al-Tashīl, koje je po svom sadržaju sveobuhvatno a svojim obimom znatno kraće, zapravo, njegovo najvažnije djelo, jer predstavlja vrhunac Ibn-Malikovih jezičkih studija i sukus njegove plodonosnog, dubokog i dugog gramatičkog iskustva. ${ }^{4}$ Značaj ovoga djela i njegove karakteristike motivisale su brojne autore nakon njega da na isto djelo pišu komentare i različite osvrte.

Iz oblasti arapskog jezika napisao je još brojna djela, a neka od njih su: Al-Muqaddima al-'asadiyya, 'Iḡäza al-ta 'rīf fì 'ilm al-tașrīf, Tuhfa almawdūd fì al-maqșūr wa al-mamdūd, Lāmiya al-'af'āl, itd. ${ }^{5}$

Ibn-Malik je autor djela Šawāhid al-tawdīh li muškilāt al-ğami ' alsahịh iz oblasti hadisa u kojem je napravio gramatički osvrt na oko sto hadisa iz djela Șahīh al-Buhāar $\bar{l}$, dok je iz oblasti kiraeta napisao djelo 'Umda al-hăfiz wa 'udda al-lāfiz.

\footnotetext{
${ }^{4}$ Hulayf, Yūsuf, Muqaddima kitāb al-Tashīl, Dār al-kitāb al-‘arabiy, Qāhira, 1967., ṣ. g.

${ }^{5}$ Ziriklī (Al-), Hayr al-dīn, $A l-' A$ 'lām, Dār al-'ilm li al-malāyīn, 2002., țab‘a 15., ș $6 / 233$.
} 


\section{Alfiyya}

Ono čime je Ibn-Malik ostao prepoznat u svojim krugovima jeste djelo Alfiyya iz oblasti gramatike arapskog jezika koje je napisao u stihovima, što nije bila nepoznanica $u$ arapskim naučnim krugovima. Nema sumnje da je ovo djelo imalo ključnu ulogu u velikoj popularnosti koju je uživao Ibn-Malik među svojim savremenicima, ali i među narednim generacijama. Potvrdu toga vidimo u riječima Teufika Muftića koji o Alfiyyi kaže: „Svojim uprošćenim i svrsihodno raspoređenim materijalom ta knjiga je postigla veliku popularnost i postala vrlo raširen udžbenik. Međutim, zbog svoje konciznosti izazvala je potrebu mnogih komentara. $" 6$

Pojava pisanja naučnih djela u stihovima je među Arapima poznata kao „edukativna poezija (al-ši'r al-ta 'līmiy)“. Naime, mnoštvo je djela koja su napisana na ovaj način, a među njima možemo istaći Alfiyyu od Irakija (al-'Irāqiyy) (1403. g.) i dvije Alfiyye od Sujutija (al-Suyūtiyy) (1505. g.), jednu iz oblasti hadisa i drugu iz oblasti arapskog jezika, Šatibijju od Šatibija (al-Šātibiyy) (1194. g.) iz oblasti kiraeta, Ğawhara al-tawḥ̄d Ibrahima Lakkanija ('Ibrāhīm al-Laqqāniy) (1632. g.) iz oblasti islamskog vjerovanja, kao i brojna naučna djela napisana iz islamsko-pravne nauke, ali i drugih znanosti.

Ova pojava je bila toliko raširena do granice da ne postoji naučna disciplina a da iz nje nije napisano djelo u formi ,edukativne poezije“. Ukoliko bi usporedili sve vrste ovakvih djela iz svih naučnih oblasti, došli bi do zaključka da je Ibn-Malikova Alfiyya, bez imalo sumnje, najprihvaćenije i najčuvenije djelo te vrste i obima. Čak šta više, kada se $\mathrm{u}$ naučnom smislu spomene termin alfiyya, onda se prevashodno misli na Ibn-Malikovu Alfiyyu, što najbolje govori o kakvom impozantnom djelu se radi. ${ }^{7}$ C̆ak je zasjenila brojna djela pisana $u$ poetskoj formi iz iste oblasti, tj. gramatike arapskog jezika, poput Alfiyye Sujutija (1505. g.) i Alfiyye Ibn-Mu'tija ('Ibn Mu'țiy) (1231. g.).

Ukoliko bi tragali za motivom kojim su se njihovi autori rukovodili mogli bi doći do različitih zaključaka, ali jedan od njih se posebno

\footnotetext{
${ }^{6}$ Muftić, Teufik, Gramatika arapskog jezika, str. 30.

7 Tammām, 'Ahmad, 'Ibn Mālik - șāḥib al-'Alfiyya, https://uqu.edu.sa/page/ar/103339 (preuzeto: 18.03.2016.)
} 
nameće, a to je velika posvećenost Arapa memorisanju i poeziji općenito. Poezija je bila i ostala odlika Arapa od predislamskog perioda do dana današnjeg, a posvećenost Arapa memorisanju je bila izražena kroz čitavu povijest, od memorisanja Kur'ana, arapske poezije, do savremenog obrazovnog sistema $\mathrm{u}$ arapskim zemljama koji se $\mathrm{u}$ značajnoj mjeri zasniva na memorisanju.

Osim ova dva načina putem kojih je Ibn-Malik davao naučni doprinos, on je pisao komentare na pojedina svoja djela, kao što je to slučaj sa djelima Šarḥ al-Käfiya al-Šāfiya i Šarh Tuḥfa al-mawdūd. Iz toga se da zaključiti da je, u samom početku, pisao što kraća djela, kako bi se lakše naučila i memorisala, nakon čega bi posvetio pažnju komentarisanju istih.

Alfiyya Ibn-Malika, kako joj i naslov kaže (ar. 'alf - hiljada), sastoji se od 988 stihova, a napisana je u metričkom stihu ,rağaz“. Ona sadrži sva najznačajnija gramatička poglavlja iz arapskog jezika, a početak Alfiyye je posvećen poglavlju o govoru (kalām) i onome od čega se on sastoji.

Nakon uvodnih sedam stihova o autoru i namjeri pisanja ove poezije, te o superiornosti njegove Alfiyye, početak Alfiyye glasi ovako:

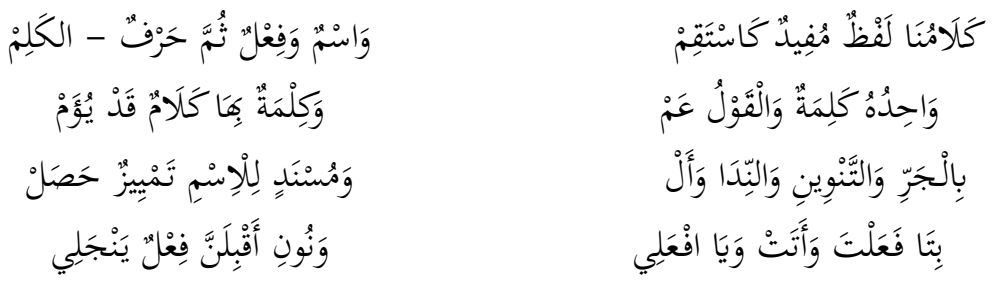

A završetak glasi ovako:
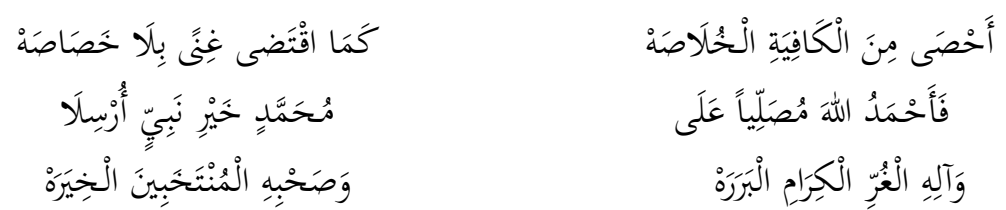

Alfiyya tretira brojne morfološko-sintaksičke teme. Prvi stihovi govore općenito o govoru (kalām), zatim o promjenjivoj (mu'rāb) i nepromjenjivoj vrsti riječi (mabnī), te određenom i neodređenom članu, a djelo završava poglavljem o aneksiji ('ị̣āfa). 


\section{Komentari Alfiyye}

Brojnost autora koji su napisali komentar na Alfiyyu najbolje govore kakav je ugled uživala među stručnjacima te i narednih generacija. Komentatori su se međusobno natjecali ko će kvalitetnije i različitije napraviti komentar ovoga vrsnog djela i time zauvijek ostati upamćeni među budućim generacijama. To je razlog činjenice da broj komentara Alfiyye prelazi četrdeset komentara, među kojima je i komentar samog Ibn-Malika.

Podatak koji kaže da je Ibn-Malikova Alfiyya jedan od najčešćih djela koje su najistaknutiji stručnjaci arapskog jezika komentarisali i koji je i dan-danas predmet izučavanja i memorisanja - najbolje govori o kakvom se djelu i autoru radi.

Najpoznatiji komentari Alfiyye su:

1. 'Awḍah al-masālik Ibn-Hišama el-Ensarija ('Ibn Hišām al-'Anșāriyy) (1359. g.), koji se smatra jednim od najrasprostranjenijih i najprihvaćenijih komenatara, posebno verzija koju je naučno valorizovao Muhjiddin Abdul-Hamid (Muhyī al-dīn 'Abd al-Ḥamīd),

2. Šarh 'Ibn 'Aqūl Behauddina b. 'Akila (Bahā' al-dīn 'ibn 'Aqīl) (1367. g.), kojeg je, također, naučno valorizovao Muhjiddin Abdul-Hamid i koji je svojim jednostavnim pristupom naišao na lijep prijem javnosti,

3. Minhāg al-sālik Nuruddina Muhammeda Isaa el-Ašmunija (Nūr aldīn Muḥammad 'lı̄ā al-'Ašmūnī) (1522. g.), koji se smatra najopsežnijim komentarom od svih prethodnih.

Pojedini autori su vršili gramatičku analizu stihova Alfiyye, poput Halida el-Ezharija (Hālid al-'Azhariyy) (1499. g.) koji je na tu temu napisao čitavu knjigu koja nosi naziv Tamrīn al-țullāb fì șinā'a al'i r rāb, dok su drugi posvetili pažnju Alfiyyi na način da su pojasnili sve argumente koje su komentatori Alfiyye koristili u svojim djelima, kao što je to učinio Bedruddin el-Ajni (Badr al-dīn al-'Aynī) (1451. g.) u svom djelu Al-Maqāsid al-naḩwiyya fì šarh šawāhid šurūh al-'alfiyya.

Možda će sljedeće riječi dr. Mehmeda Kice najljepše ilustrirati IbnMalikovog doprinos razvoju arapske gramatike i značaj komentara koji su uslijedili na njegovo djelo Alfiyya: „Udžbenička literatura je, međutim, svoj najvrijedniji eksponat dobila djelom Muhammeda ibnMalika Hulāṣa al-'Alfiyya, napisanim u stihovima, koje je polučilo 
mnogobrojne komentare, a među njima se najviše ističu onaj od IbnAkila i el-Ašmunija. Kasnije je nastao znamenit broj glosa na njihove komentare, a i danas se na časovima jezikoslovne znanosti ovim komentarima posvećuje znatna pažnja“. 8

\section{Neki od specifičnih stavova Ibn-Malika}

Ibn-Malik u svojim djelima je koristio selektivni metod, gdje je iznosio gramatička mišljenja koja je smatrao jačim i utemeljenijim, što je bio njegova odlika u svim njegovim djelima, kako to navodi značajan broj istraživača.

Ovaj metod temelji se na spajanju različitih mišljenja i odabiru najutemeljenijeg i najjačeg, s jasnim opredjeljenjem da se prednost daje olakšavanju, preferiranju jačeg stava $\mathrm{i}$ inovativnosti.

U svojim djelima se značajno oslanjao na argumentaciju kur'anskim tekstovima (uvažavajući pri tome sve modalitete učenja Kur'ana), zatim hadiskim predajama (bez posebnih uslovljavanja, kao što je to slučaj kod pojedinih učenjaka) i arapskom poezijom. Značajan iskorak je napravio $\mathrm{u}$ korištenju hadiskih predaja kao osnove za gramatička pravila, kao i davanju prednosti hadiskim predajama u odnosu na poeziju, što je prije njega bila rijetkost. To je što ga čini prepoznatljivim, jer je on prvi arapski filolog koji je u velikoj mjeri koristio hadiske predaje kao argument $\mathrm{u}$ arapskom jeziku. Iako su drugi, poput Ebu-Ali el-Farisija ('Abū 'Aliyy al-Fārisiyy) (987. g.) i IbnDžinnija ('Ibn Ğinniyy) (1002. g.), koristili hadiske tekstove kao osnov za pravila arapskog jezika prije njega, ali niko prije njega nije pridavao toliku pažnju hadiskim tekstovima pri normiranju arapskog jezika.

U djelima Ibn-Malika često nalazimo da preferira mišljenja drugih gramatičkih škola (basranske, kufske ili bagdadske), ali često ima samostalno mišljenje koje odudara od stavova drugih gramatičkih škola. Zato pojedini autori smatraju da je imao svoj zaseban pravac, po kojem je bio prepoznatljiv.

\footnotetext{
${ }^{8}$ Kico, Mehmed, Arapska jezikoslovna znanost, Fakultet islamskih nauka, Sarajevo, 2003., str. 87.

9 Jahić, Mustafa, Arapski jezik u islamskim naukama, El-Kalem, Sarajevo, 2012., str. 228.
} 
On je odvažno iznosio i branio svoje stavove, iako će zbog toga biti predmet kritike mnogih. Jedan od njegovih žestokih kritičara jeste $\mathrm{i}$ Ebu-Hajjan el-Garnati ('Abū Hayyān al-Ġarnāțiyy) (1344.), koji je „kritizirao Ibn-Malika zbog njegovog naslanjanja na tradiciju Poslanika, s.a.v.s., i navođenja primjera iz nje, jer je smatrao da je to prepričavan tekst preko lanca ravija među kojima je bilo i onih koji nisu bili Arapi, za koje nije teško pretpostaviti da su mogli griješiti u jeziku. “10

Jedan od primjera preferiranja mišljenja različitih gramatičkih škola jeste da se u okviru poetske slobode može dozvoliti da se imenica koristi u nepotpunoj deklinaciji, kao i stav kufanskih gramatičara, koji

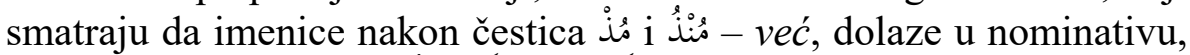

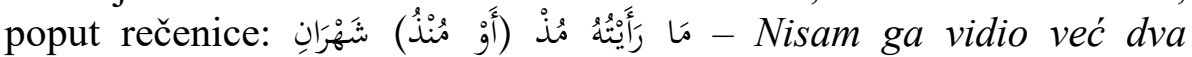
mjeseca. $^{11}$

Jedan od primjera stavova koje je Ibn-Malik preferirao, a koji pripadaju kufskoj gramatičkoj škol jeste stav koji dozvoljava da se jednina može

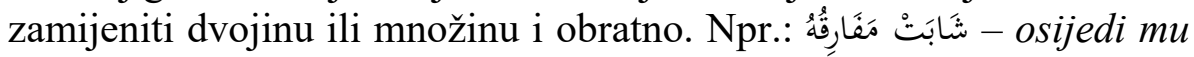
razdiok kose (korištena je riječ riječ مَفْرَق -razdiok kose u množini), iako je logički dozvoljeno koristiti riječ مَفْرَفْ isključivo u jednini, tj. onda bi glasilo شَابَ مَفْرَُُهُ - osijedi mu razdiok kose, ali je korišten u množini jer je Ibn-Malik smatrao da je ispravno da jednina zamijeni dvojinu ili množinu i obratno.

Primjer stavova kojim se razlikuje od ostalih jeste iznalaženje nove

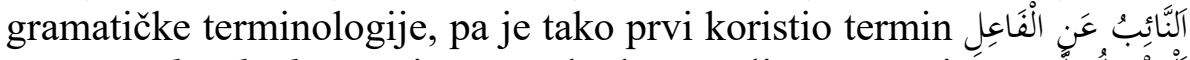

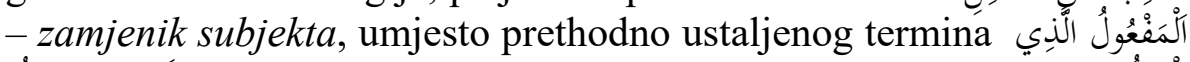

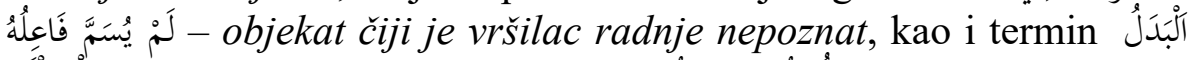

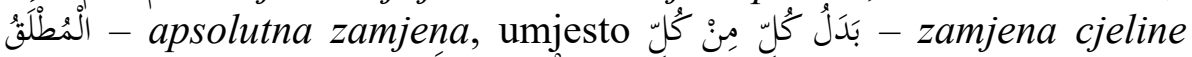

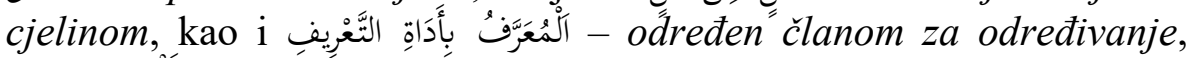

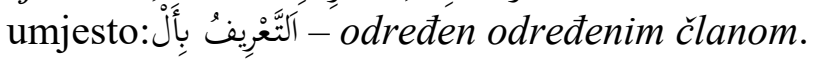

${ }^{10}$ Trnka Uzunović, Amira, Abu Hayyan al-Garnati-gramatičar i mufessir, Zbornik radova Fakulteta islamskih nauka XXX, Sarajevo, 2011., str. 340.

${ }^{11}$ Dayf, Šawq1̄, Al-Madāris al-nahwwiyya, ș. 312. 


\section{Zaključak}

Biografi koji su pisali o Ibn-Maliku navode da je bio skroman, povučen i lijepoga odgoja. Bio je strpljiv i uporan u traženju nauke i čestom iščitavanju nove literature. Odlikovao se tačnošću i preciznošću, a ostaće upamćen kao jedan od najvećih autoriteta $u$ arapskom jeziku, iako ni u drugim naučnim oblastima nije zaostajao.

Svojim stavovima je dokazao da nije puki sljedbenik neke od gramatičkih škola, nego da je bio širokih vidika i da se povodio za onim do čega ga dovedu vlastiti zaključci, zbog čega je često bio na meti kritičara.

Nema sumnje da je svojim naučnim doprinosom obilježio period $u$ kojem je živio i iza sebe ostavio djela koja će biti predmet brojnih komentara i analiza. Njegova djela su postala jedna od najrelevantnijih iz oblasti arapske gramatike i za njega se s pravom može reći da je „prvak svih gramatičara i filologa svoga vremena.“"

Djelo Alfiyya je proslavilo Ibn-Malika do te mjere da je bio uzor drugima u ovom načinu pisanja djela, ali i predmet brojnih komentara, koji, kako smo to naveli u radu, prelaze brojku od četrdeset komentara, što samo za sebe govori kakav značaj ima njegova Alfiyya.

\section{Literatura}

1. Ḍayf, Šawqī, Al-Madāris al-naḥwiyya, Dār al-ma ‘ārif, Al-țab'a alrābi ‘a, Al-Qāhira, 1979.

2. Hulayf, Yūsuf, Muqaddima kitāb al-Tashīl, Dār al-kitāb al-'arabiy, Qāhira, 1967.

3. Jahić, Mustafa, Arapski jezik u islamskim naukama, El-Kalem, Sarajevo, 2012.

4. Kico, Mehmed, Arapska jezikoslovna znanost, Fakultet islamskih nauka, Sarajevo, 2003.

5. Muftić, Teufik, Gramatika arapskog jezika, Ljiljan, Sarajevo, 1998.

6. Tammām, 'Ahmad, 'Ibn Mālik - șāhịb al-'Alfiyya, https://uqu.edu.sa/page/ar/103339

7. Trnka Uzunović, Amira, Abu Hayyan al-Garnati-gramatičar $i$ mufessir, Zbornik radova Fakulteta islamskih nauka XXX, Sarajevo, 2011.

8. Ziriklī (Al-), Hayr al-dīn, Al-'A'lām, Dār al-'ilm li al-malāyīn, 2002., țab'a 15. 


\section{Hajrudin Hodžić, PhD}

\section{IBN MALIK AND HIS ALFIYYA}

\section{Abstract}

Ibn-Malik lived in the 13th century, or 7th century AH and completely marked the century in which he lived by his work and scientific contributions.

His scientific life was extremely fruitful. He enriched the disciplines in which excelled with exceptional works. His works have found fertile ground in the generation that came after him. He wrote works in the field of Arabic grammar, philology, Arabic metrics, Qira'at and Hadith.

He left behind a number of scientific works, some in the form of prose, and other in the form of "educational poetry". Alfiyya is his by far the most important work, which made hism famous and preserved memory of him to this day.

Due to his overall contribution to the grammar of the Arabic language, many rank Ibn Malik immediately behindSibawayh, the father of Arabic grammar, and compare his life with the beginning of a new phase in the history of Arabic grammar.

Keywords: Arabic, Ibn Malik, Alfiyya, commentary of Alfiyya, Andalusia 


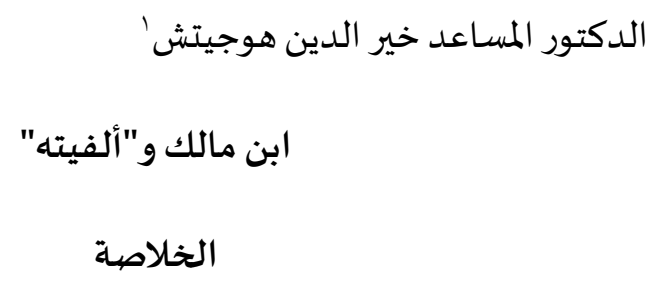

عاش ابن مالك في القرن الثالث عشر الميلادي أو السـابع الهجري وقد كان بعمله وإسهامه العلمي من أشهر الأعلام ذلك القرن.

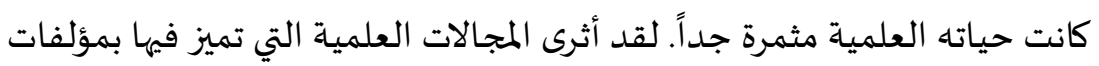

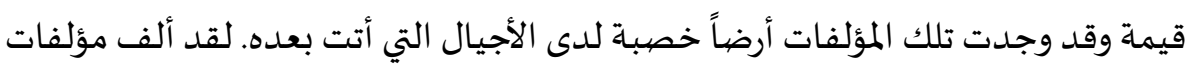
في مجال النحو، علم اللغة، العروض، القراءات والحديث.

لقد خلف وراءه مؤلفات علمية عديدة، بعضها على شكل النثر وبعضها على شكل النه "الشعر التعليمي"، ولكن لاشك أن أشهر كتبه الذي حفظ له الذكر إلى يومنا هذا هو كتابه

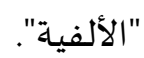
بسبب إسهامه الكلي في مجال النحو، فإن الكثيرين يجعلون مكانته بعد سيبويه، أبي النحو العربي، مباشرة ويجعلون حياته بداية مرحلة جديدة في تاريخ النحو العربي.

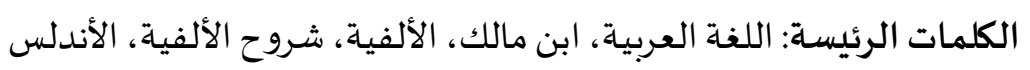

